\title{
Effects of Diode Laser, Gaseous Ozone, and Medical Dressings on Enterococcus faecalis Biofilms in the Root Canal Ex Vivo
}

\author{
Kerstin Bitter, ${ }^{1}$ Alexander Vlassakidis, ${ }^{1}$ Mediha Niepel, ${ }^{1}$ Daniela Hoedke, ${ }^{2}$ \\ Julia Schulze, ${ }^{3}$ Konrad Neumann, ${ }^{4}$ Annette Moter, ${ }^{5}$ and Jörn Noetzel ${ }^{1,6}$ \\ ${ }^{1}$ Department of Operative Dentistry and Preventive Dentistry, CharitéCentrum 3, \\ Charité-Universitätsmedizin Berlin, Aßmannshauser Str. 4-6, 14197 Berlin, Germany \\ ${ }^{2}$ Department of Periodontology and Synoptic Dentistry, CharitéCentrum 3, Charité-Universitätsmedizin Berlin, \\ Aßmannshauser Str. 4-6, 14197 Berlin, Germany \\ ${ }^{3}$ Institute of Microbiology and Hygiene, CharitéCentrum 5, Charité-Universitätsmedizin Berlin, Sylter Straße 2, 13353 Berlin, Germany \\ ${ }^{4}$ Department of Medical Informatics, Biometry and Epidemiology, CharitéCentrum 4, Charité-Universitätsmedizin Berlin, \\ Hindenburgdamm 30, 12203 Berlin, Germany \\ ${ }^{5}$ Biofilmcenter, German Heart Institute, Deutsches Herzzentrum Berlin (DHZB), Hindenburgdamm 30, 12203 Berlin, Germany \\ ${ }^{6}$ Private Practice Mutlangen, Schillerstraße 5, 73557 Mutlangen, Germany
}

Correspondence should be addressed to Kerstin Bitter; kerstin.bitter@charite.de

Received 1 January 2017; Accepted 15 March 2017; Published 10 April 2017

Academic Editor: Evandro Piva

Copyright (C) 2017 Kerstin Bitter et al. This is an open access article distributed under the Creative Commons Attribution License, which permits unrestricted use, distribution, and reproduction in any medium, provided the original work is properly cited.

The objective was to compare the antibacterial effects of adjunctive disinfection using diode laser and gaseous ozone compared to the medical dressings calcium hydroxide $\left(\mathrm{Ca}(\mathrm{OH})_{2}\right)$ and chlorhexidine gel (CHX-Gel) on Enterococcus faecalis biofilms in human root canals ex vivo. Root canals of 180 human extracted teeth were infected by E. faecalis and divided into 3 main groups (G): G1, control; $\mathrm{G} 2$, instrumentation and irrigation using $0.9 \% \mathrm{NaCl}$; G3, instrumentation and irrigation using $1 \% \mathrm{NaOCl}$. In each main group, the following treatments were applied: gaseous ozone, diode laser, and medical dressings of $\mathrm{Ca}(\mathrm{OH})_{2}$ or $\mathrm{CHX}-\mathrm{Gel}$ for 7 days $(n=15)$. Reduction of colony forming units (CFUs) inside the root canal of planktons and frequencies of adherent bacteria after treatment were calculated. Bacterial reduction was significantly affected by the irrigation protocol $(p<0.0005)$ and the disinfection method $(p<0.0005)$, and a significant interaction between both factors could be observed $(p<0.0005$; ANOVA). In G3 (instrumentation using $1 \% \mathrm{NaOCl})$, no significant effect of disinfection methods could be demonstrated on planktonic bacteria $(p=0.062$; ANOVA) and frequencies of adherent bacteria $(p>0.05$; chi-square test). Instrumentation and irrigation using NaOCl combined with ozone or laser application resulted in comparable bacterial reduction on E. faecalis to the application of medical dressings.

\section{Introduction}

The control of an endodontic infection is affected by the following factors: host defense, instrumentation and irrigation of the root canal system, locally used intracanal medicaments between appointments, the root canal filling, and the coronal restoration [1]. E. faecalis has been described as the most frequent species found in retreatment cases with a prevalence of up to $90 \%[2,3]$. One major key element of successful one- or multiple-visit root canal treatment is the chemomechanical debridement of the root canal including instrumentation and irrigation using antimicrobial solutions [4]. Anatomical complexities of the root canal system as well as the recalcitrance of microbial biofilms often demonstrate a serious challenge to effective root canal disinfection $[5,6]$. Therefore, in the treatment of apical periodontitis, intracanal medication has been recommended to eliminate bacteria from the root canal system that survived instrumentation and irrigation [7]. The intracanal medicament calcium hydroxide $\left(\mathrm{Ca}(\mathrm{OH})_{2}\right)$ is strongly alkaline and dissociates into calcium and hydroxide ions in aqueous solution resulting in an antibacterial effect and a tissue-dissolving capacity; however, 
the antimicrobial activity seems to depend on the direct contact of $\mathrm{Ca}(\mathrm{OH})_{2}$ with the bacteria $[8,9]$. Because of its low solubility and diffusibility, $\mathrm{Ca}(\mathrm{OH})_{2}$ reveals a reduced effect against bacteria located in pulpal remnants, crevices, and isthmi in the canal system and the dentinal tubules especially against $E$. faecalis [10]. Moreover, complete removal of $\mathrm{Ca}(\mathrm{OH})_{2}$ from the root canal system irrespective of the irrigation solution or system is difficult to achieve because of the complexity of its anatomy [11-13]. Remnants of $\mathrm{Ca}(\mathrm{OH})_{2}$ may impair the sealing ability of the root canal filling $[14,15]$ and therefore alternative options concerning further intracanal medicaments or disinfection methods are of interest.

Chlorhexidine (CHX) is a synthetic cationic bisguanide that is positively charged. The hydrophobic and lipophilic molecule interacts with phospholipids and lipopolysaccharides on the cell membrane of bacteria and is able to enter the bacterial cells through active or passive transport mechanisms [16]. A randomized clinical trial analyzed the antibacterial effectiveness of the intracanal medicaments $\mathrm{Ca}(\mathrm{OH})_{2}$ and 2\% CHX-Gel in teeth with chronic apical periodontitis and revealed a comparable effect [17]. Data of ex vivo studies demonstrated that 2\% CHX-Gel as an intracanal medicament was more effective against $E$. faecalis compared to $\mathrm{Ca}(\mathrm{OH})_{2}$ $[18,19]$. Nevertheless, the antimicrobial activity of CHX gel is affected by the time it remains inside the root canal because it is not able to act as a physical barrier [20]. Both intracanal medicaments require a second appointment to remove the medicament; consequently, a single-visit approach is not possible and complete removal of the medicament from the root canal system remains questionable. Moreover, reinfection of the root canal system is possible to occur during appointments. In addition, recent clinical data and metaanalyses demonstrated no significant differences of success rate and postoperative pain of single-visit or multiple-visit endodontic treatment [21-24]. However, during one-visit root canal treatment, adequate disinfection of the whole root canal system has to be ensured within one session.

Further disinfection methods besides the application of intracanal medicaments and irrigation solutions have been suggested to enhance the removal of residual bacteria from the root canal system. Ozone $\left(\mathrm{O}_{3}\right)$ is a naturally occurring gas and is an energized, unstable form of oxygen that readily dissociates back into oxygen $\left(\mathrm{O}_{2}\right)$ and singlet oxygen $\left(\mathrm{O}_{1}\right)$, which is a reactive form of oxygen and is capable of oxidizing cells. It is able to destroy biomolecules and cell walls of bacteria [25]. Ozone gas (HealOzone; KaVo, Biberach, Germany) as an adjunctive disinfection method has been suggested to be used clinically in endodontic treatment but the results of studies on its efficacy against endodontic pathogens have been inconsistent [26]. Questions remain about the optimum duration and concentration of ozone gas that should be used [27]. Ozone demonstrated an antibacterial effect on planktonic E. faecalis cells but revealed a little effect on cells embedded in a biofilm structure [27] and was not comparable with the antibacterial effect of sodium hypochlorite [27-30]. In contrast to that, another study demonstrated that gaseous and aqueous ozone were as effective as $\mathrm{NaOCl}$ and $\mathrm{CHX}$ being able to completely remove the bacterial biofilm inside the root canal ex vivo [31].
The physical effect of laser (Light Amplification by Stimulated Emission of Radiation) is based on producing a light beam with high energy density through induced emission of atoms in the laser medium. The physical interaction between laser and tissue is determined by the adsorption spectrum of the tissue. Provided that the wavelength of the laser corresponds to the adsorption spectrum of the tissue, a linear biological effect characterized by hyperthermia $\left(37-60^{\circ} \mathrm{C}\right)$, coagulation $\left(60-100^{\circ} \mathrm{C}\right)$, carbonization $\left(100-400^{\circ} \mathrm{C}\right)$, and evaporation $\left(>400^{\circ} \mathrm{C}\right)$ on tissue cells is induced [32]. The application of diode laser irradiation has been suggested as an effective adjunctive antibacterial disinfectant in the root canal [33]. The antibacterial effect of diode laser irradiation has been attributed to its greater depth of penetration up to $1000 \mu \mathrm{m}$ into the dentinal tubules when compared to the penetration depth of chemical disinfectants, which were limited to $100 \mu \mathrm{m}$ in a recent in vitro study [34]. Accordingly, Gutknecht et al. demonstrated that diode laser with $980 \mathrm{~nm}$ wavelength can eliminate $E$. faecalis up to a penetration depth of $500 \mu \mathrm{m}$ effectively [35].

Little is known about the combination of irrigation protocols and adjunctive disinfection methods possibly enabling a one-visit endodontic treatment in comparison to the conventional method of using intracanal medicaments in a multiple-visit endodontic treatment. Consequently, the aim of the present study was to analyze the antimicrobial efficacy of gaseous ozone and diode laser in combination with various irrigation protocols in comparison to the application of intracanal medicaments $\left(\mathrm{Ca}(\mathrm{OH})_{2}\right.$ and $\left.\mathrm{CHX}-\mathrm{Gel}\right)$ against $E$. faecalis biofilms in root canals of extracted human front teeth ex vivo.

The null hypothesis of the present study was that no difference in bacterial reduction between the disinfection methods and the intracanal medicaments in combination with the irrigation protocols would exist inside the root canal lumen (planktonic bacteria) and in the root canal dentin (adherent bacteria).

\section{Methods}

2.1. Sample Preparation. 180 extracted, intact, human, upper canines with a single canal without distinct curvature were obtained with written informed consent under an ethicsapproved protocol (EA4/102/14) by the Ethical Review Committee of the Charité-Universitätsmedizin Berlin, Germany, and cleaned with ultrasonic scalers (SONICFlex; KaVo, Biberach, Germany). Crowns were removed, all roots were shortened to $19.5 \mathrm{~mm}$, and all samples were sterilized using ethylene dioxide (Campus Benjamin Franklin, CharitéUniversitätsmedizin Berlin, Berlin, Germany).

Subsequently, all teeth were randomly divided into three groups $(\mathrm{G} 1-\mathrm{G} 3, n=60)$. The coronal portion of the root canals was enlarged using Gates Glidden burs size 6 to 4 . In G1 root canal enlargement was performed up to size 60 with 0.20 taper, whereas instrumentation limited to size $40,0.20$ taper, was carried out in G2 and G3 using Flexmaster rotary files (VDW, Munich, Germany). Irrigation was performed using sterile sodium chloride $(0.9 \% \mathrm{NaCl}$, pharmacy of Charité-Universitätsmedizin Berlin, Germany). After initial 

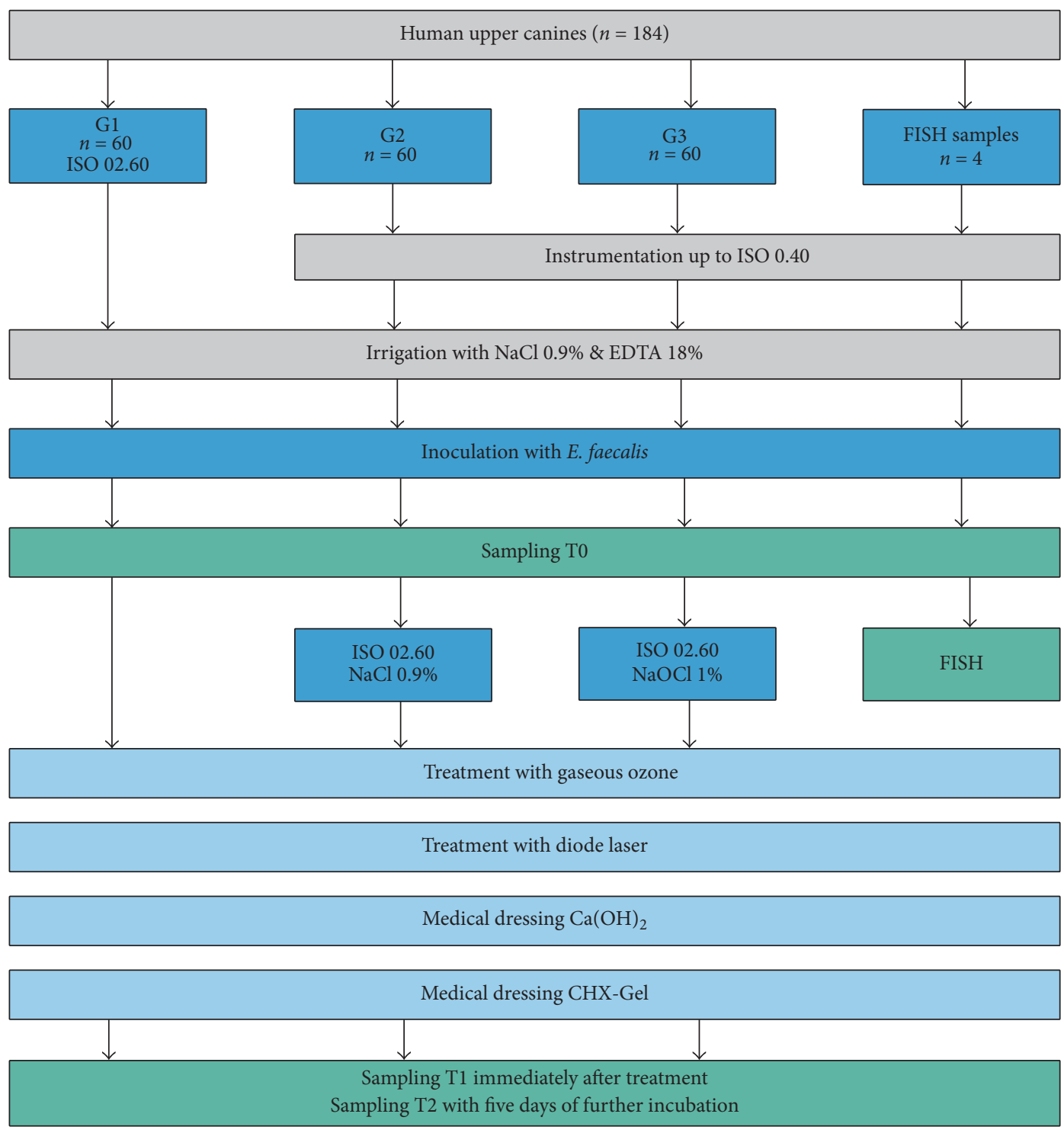

FIGURE 1: Flow chart illustrating study design and experimental procedure.

root canal instrumentation, the smear layer was removed in all samples using $18 \%$ ethylenediaminetetraacetic acid (EDTA 18\% Solution, Ultradent Products Inc., South Jordan, Utah, USA). After covering the root surfaces with nail varnish (Lilliput Nagellack, Kron 1959; Wiesbaden, Germany), each tooth was embedded into closable cryotubes (Carl Roth, Karlsruhe, Germany) using epoxy resin (Technovit 4071; Heraeus Kulzer, Hanau, Germany). Subsequently, all teeth were sterilized once again. Prior to inoculation of E. faecalis, sterility was tested by storing the teeth in sterile boxes (50 mL Falcon tubes; Sarstedt, Numbrecht, Germany) with sterile brain-heart-bouillon (BHI; SIFRIN, Berlin, Germany) at $37^{\circ} \mathrm{C}$ under anaerobic conditions for seven days. Clear bouillon after seven days indicated sterility. The whole study design is illustrated in Figure 1.
2.2. Inoculation of E. faecalis. Following sterilization, the root canals were infected with a suspension of $30 \mu \mathrm{L} \mathrm{E}$. faecalis (ATCC 29212) (optical density 0.1) in Tryptic Soy Broth (TSB, Sigma-Aldrich, St. Louis, MO, USA) with $0.25 \%$ glucose. After $24 \mathrm{~h}$ of incubation at $37^{\circ} \mathrm{C}$, the root canals were infected once again according to the procedure described above. The biofilm was incubated for six days at $37^{\circ} \mathrm{C}$ in $\mathrm{CO}_{2}$ atmosphere with daily addition of sterile TSB to ensure constant liquid levels in the root.

2.3. Root Canal Treatment. In G2 and G3 root canal enlargement to size 60 , taper 0.20 , was performed using sterile saline solution in G2 and sodium hypochlorite $(1 \% \mathrm{NaOCl}$, pharmacy of Charité-Universitätsmedizin Berlin, Germany) in G3. During instrumentation, irrigation was performed 
using $2 \mathrm{~mL}$ irrigation solution after each change of file size and final irrigation using $3 \mathrm{~mL}$ irrigation solution in each group. All root canals were dried using paper points ISO 60 (paper point ISO 60; VDW, Munich, Germany).

Subsequently, the following disinfection protocols (A-D) were immediately applied.

(A) Application of gaseous ozone was carried out with a hand piece (HealOzone plus 2131C, KaVo) using sterile, disposable silicone caps (HealOzone Delivery Cup, $6 \mathrm{~mm}, \mathrm{KaVo}$ ) and endodontic cannulas (HealOzone application cannulas, $24 \mathrm{~mm}, \mathrm{KaVo}$ ). The cannulas were dropped into the root canals and gaseous ozone was applied twice for $60 \mathrm{~s}$ with a flow rate of $100 \mathrm{~mL} / \mathrm{min}$ in each period (ozone concentration $2100 \mathrm{ppm}$ which is equivalent to $4.49 \mathrm{~g} / \mathrm{m}^{3}$ ).

(B) Diode laser application was executed via the endodontic program of the GENTLEray 980 Laser (KaVo, Biberach, Germany) with the following setting: $2.5 \mathrm{~W}$ at an average of $0.8 \mathrm{~W}$, wavelength $980 \mathrm{~nm}$. The glass fiber of the diode laser (Bare Fiber NIR Q $300 \mathrm{~K}, 200 \mu \mathrm{m}$; Asclepion Laser Technologies, Jena, Germany) was dropped carefully into the root canals at working length $-1 \mathrm{~mm}$. The fiber was moved 4 times in a rotary manner along the dentin surface of each root canal wall in apical-coronal direction with a speed of $3 \mathrm{~mm}$ per second for $10 \mathrm{~s}$.

$(\mathrm{C}$ and $\mathrm{D})$ Medical dressings of $\mathrm{Ca}(\mathrm{OH})_{2}$ (UltraCal XS, Ultradent, South Jordan, Utah, USA) and CHX-Gel (Chlorhexamed 1\% Gel, GlaxoSmithKline, London, UK) were applied into the root canal in an apical-coronal movement with sterile disposable cannula until the canal was completely filled and thereafter the samples were stored for 7 days at $37^{\circ} \mathrm{C}$.

\subsection{Sample Preparation for Microscopic Biofilm Evaluation.} To confirm the establishment of biofilms in the root canals, four additional specimens were inoculated with E. faecalis as described above and fixated in $3.7 \%$ paraformaldehyde (3 vols.) in PBS (1 vol.) for $16 \mathrm{~h}$ at $4^{\circ} \mathrm{C}$ and then washed with sterile PBS and stored in a mixture of $100 \%$ ethanol and PBS $(1: 1)$. The root canals were filled using cold polymerizing resin (Technovit 8100; Heraeus Kulzer, Hanau, Germany) and the roots were also embedded using the same material. The roots were sectioned horizontally to the long axis of the root using a circular saw (Leitz 1600, Leitz GmbH \& Co. KG, Oberkochen, Germany) and ground flat (grinding system Exakt, 400 CS, grinding paper P 1200, Exact, Apparatebau). Thereafter, unspecific DNA staining with a blue fluorescent dye (DAPI: 4',6-diamidino-2-phenylindole dihydrochloride, Thermo Fisher, Waltham, USA) was performed. Imaging was performed using an epifluorescence microscope (Axioplan 2, Zeiss, Jena, Germany).

2.5. Sampling of Planktonic and Adherent Bacteria and Determination of Colony Forming Units. Sampling of bacteria was performed at three different time points (T0-T2): before treatment (T0), immediately after therapy (T1), and after further incubation (T2) of exemplary samples that revealed no bacterial count after T1. Sampling of planktonic bacteria from the liquid of each canal was determined by placing one sterile paper point size 40 (paper point ISO 40; VDW,
Munich, Germany) into the root canal until it was soaked up with fluid up to the mark of $18 \mathrm{~mm}$. Each paper point was placed into $1995 \mu \mathrm{L}$ sterile $\mathrm{NaCl}$, vortexed for $30 \mathrm{~s}$, and diluted serially before plating on culture plates (Columbia agar plates with 5\% sheep blood; Heipha, Eppelheim, Germany).

Bacteria from dentin were taken by moving a Hedstroem file ISO size 60 three times along the dentin wall from apical to coronal position and placing the file into $1.995 \mathrm{~mL} \mathrm{NaCl}$ in a cryotube. After vortexing for $30 \mathrm{~s}$, the bacterial fluid was plated on culture plates.

All plates were incubated in $\mathrm{CO}_{2}$ atmosphere for $24 \mathrm{~h}$ at $37^{\circ} \mathrm{C}$. The number of colony forming units (CFUs) was counted.

2.6. Statistical Evaluation. Kruskal-Wallis test was performed for comparison of baseline infection.

Before and after therapy, CFU counts of the planktonic bacteria were transformed in $\log _{10}$ scale and logarithmic reduction factors were calculated. Univariate variance analyses using logarithmic reduction factor as a dependent variable were carried out to determine the effect of irrigation protocol (factor 1) and of disinfection method (factor 2). Post hoc tests (Tukey's HSD) were performed to assess differences in the effects of different irrigation protocols and disinfection methods.

Categories of final bacterial counts were applied for paper point and dentin samples, respectively $(1<$ detection limit; $2 \leq$ 47,500 CFUs/mL or $\leq 20,000 \mathrm{CFUs} / \mathrm{mg} ; 3>47,500 \mathrm{CFUs} / \mathrm{mL}$ or $>20,000 \mathrm{CFUs} / \mathrm{mg}$ ). The distribution of all values for this classification was recorded in cross tabulations and chisquare tests (corrected $p$ value, $p=0.0083$ ).

All analyses were performed using IBM SPSS Statistics 22 (SPSS, IBM, Munich, Germany).

\section{Results}

3.1. Fluorescence Detection of E. faecalis Biofilms. Figures 2(a)-2(c) reveal successful formation of a multilayered biofilm of E. faecalis in the root canal located on the root canal dentin in the root canal lumen as well as inside the dentinal tubules.

3.2. Quantitative Evaluation. The mean value of the initial bacterial count of all 180 samples was calculated at $2.57 \times$ $10^{6} \mathrm{CFUs} / \mathrm{mL}\left(\mathrm{SD} \pm 2.62 \times 10^{6}\right)$. No significant differences between groups were detected at baseline $(p=0.057$, Kruskal-Wallis test).

3.2.1. CFUs of Planktonic Bacteria from the Root Canal Lumen. Logarithmic bacterial reduction was significantly affected by the irrigation protocol $(p<0.0005)$ and the disinfection method ( $p<0.0005)$, and a significant interaction between both factors could be observed ( $p<0.0005$; ANOVA). Concerning the irrigation protocol, irrigation using $1 \% \mathrm{NaOCl}$ revealed significantly higher bacterial reduction compared to G1 and G2 ( $p<0.0005$; Tukey's HSD). Disinfection using $\mathrm{Ca}(\mathrm{OH})_{2}$ revealed significantly higher bacterial reduction compared to all other methods $(p \leq 0.014)$, whereas laser application revealed significantly lower bacterial reduction 


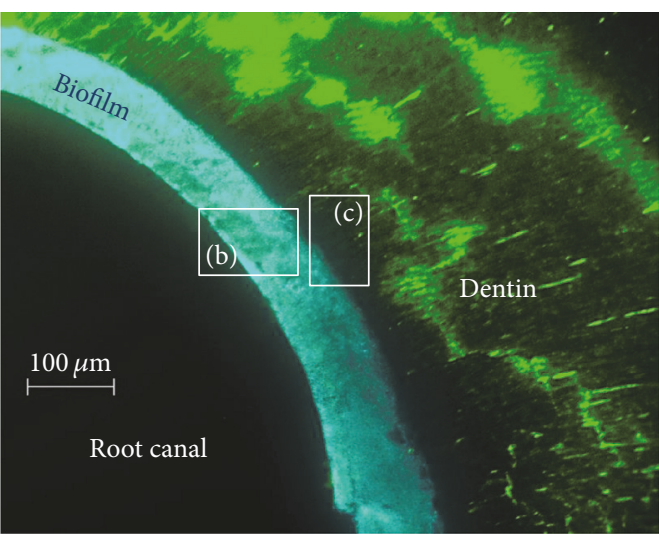

(a)

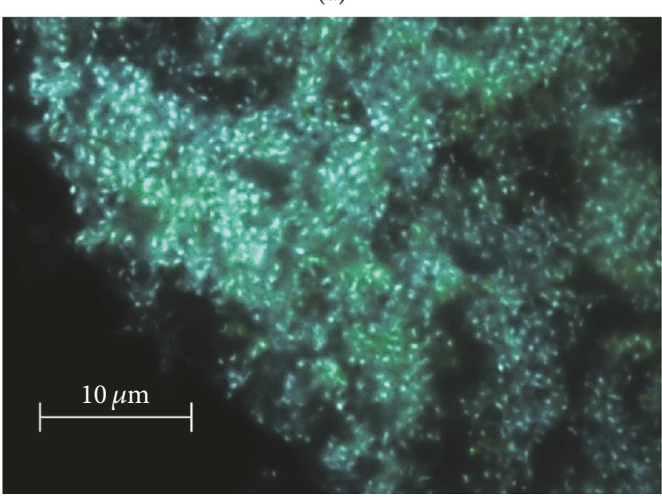

(b)

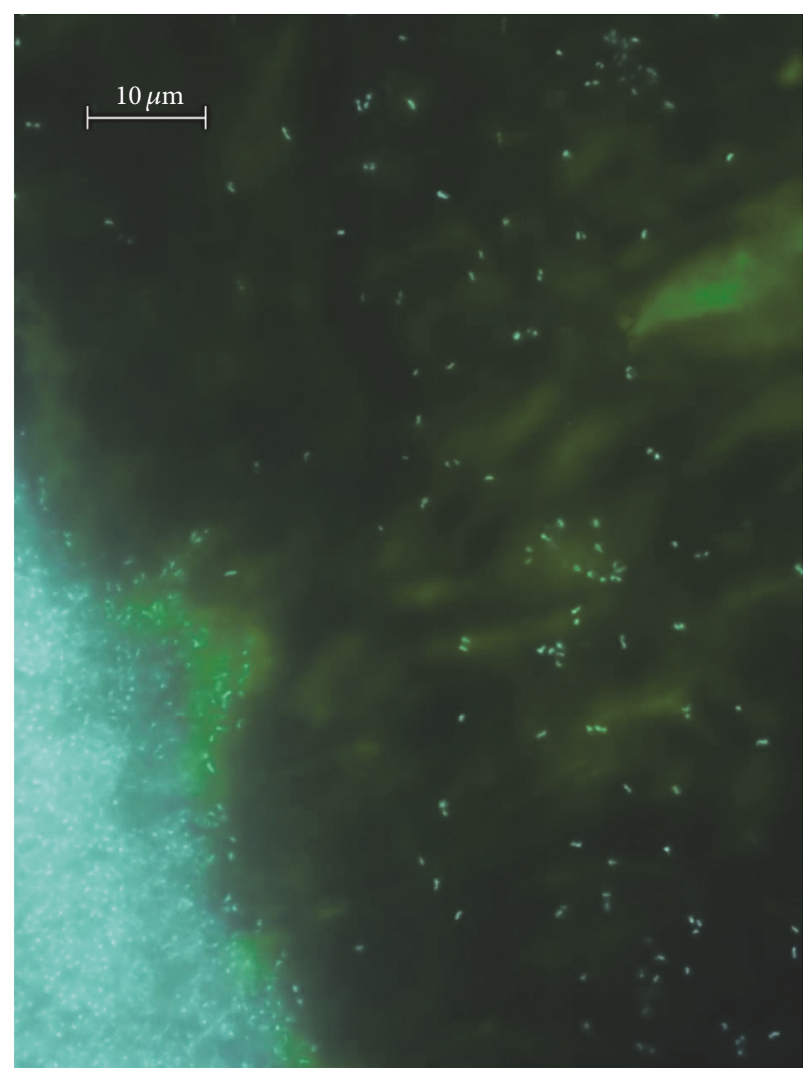

(c)

Figure 2: (a) Overview of a cross section of the root canal; the blue stained multilayered biofilm of E. faecalis is clearly visible; green background fluorescence of the root canal dentin. The white boxes indicate the areas that are displayed in (b) and (c). (b) Higher magnification of the multilayered biofilm located on the root canal dentin. (c) A mature biofilm has been formed inside the root canal and single bacterial cells are visible inside the dentinal tubules.

compared to ozone treatment $(p=0.014)$ and the investigated medical dressings $(p<0.0005)$. The application of ozone and CHX-Gel did not differ with respect to bacterial reduction ( $p=0.222$; Tukey's HSD).

Analyses with respect to the applied irrigation protocol revealed for G1 (no further instrumentation) and G2 (instrumentation with $\mathrm{NaCl}$ ) a significant effect of the disinfection method on bacterial reduction ( $p<0.0005$; ANOVA). For G1, application of the medical dressings revealed significantly higher bacterial reduction compared to laser or ozone treatment ( $p \leq 0.001$; Tukey's HSD). For main group G2 (instrumentation using $\mathrm{NaCl}$ ), laser treatment revealed significantly lower bacterial reduction compared to all other disinfection methods ( $p \leq 0.011$; Tukey's HSD). In main group G3 (instrumentation using $1 \% \mathrm{NaOCl}$ ), no significant effect of the disinfection method could be demonstrated ( $p=$ 0.062; ANOVA) (Figure 3).

3.2.2. Analyses of Adherent Bacteria. In G1, medical dressings using $\mathrm{Ca}(\mathrm{OH})_{2}$ or $\mathrm{CHX}-\mathrm{Gel}$ revealed significantly lower categories of $\mathrm{CFU}$ counts compared to ozone and laser treatment ( $p \leq 0.004$; chi-square test), whereas the latter did not differ significantly ( $p=1.000$; chi-square test). In G2 and G3, no significant differences between groups could be detected ( $p>0.0083$; chi-square test) (Figure 4).

Exemplary dentin samples with CFU levels below detection level from each group were further incubated for 5 days and bacterial growth was evaluated. Significant differences between subgroups were detected $(p<0.0005$; chi-square test). Medical dressings using $\mathrm{CHX}-\mathrm{Gel}$ or $\mathrm{Ca}(\mathrm{OH})_{2}$ revealed in $85 \%$ and $52.6 \%$ of all incubated samples no further bacterial growth whereas ozone and laser treatment demonstrated bacterial regrowth in $78.6 \%$ and $81.8 \%$ of all samples.

\section{Discussion}

The present study analyzed the antimicrobial efficacy of gaseous ozone and diode laser application without further instrumentation and irrigation as well as in combination with an antibacterial irrigation protocol in comparison to the application of intracanal medicaments against E. faecalis biofilms in root canals of extracted human upper canines ex vivo.

The null hypothesis of the present study has to be partly rejected because significant differences with respect to the instrumentation and irrigation protocol as well as 


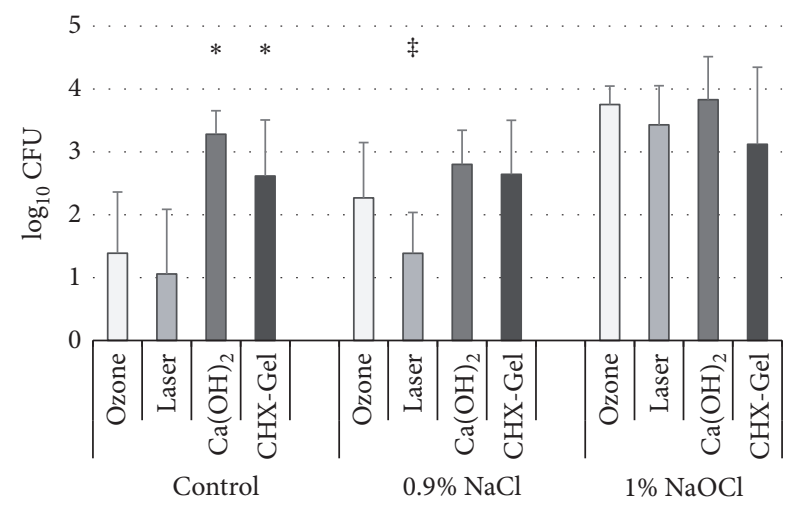

FIGURE 3: Logarithmic bacterial reduction of planktonic bacteria with respect to main groups 1-3 and the respective disinfection methods. In the control group without irrigation and instrumentation, intramedical dressing with $\mathrm{Ca}(\mathrm{OH})_{2}$ or $\mathrm{CHX}-\mathrm{Gel}$ revealed significantly higher bacterial reduction compared to both ozone and laser treatment indicated by $\left({ }^{*} p \leq 0.001\right.$; Tukey's HSD). After irrigation using $0.9 \% \mathrm{NaCl}$, laser application resulted in a significant lower bacterial reduction compared to all other treatments indicated by ( ${ }^{\ddagger} p \leq 0.011$; Tukey’s HSD). No significant differences between groups could be observed when irrigation was performed with $1 \%$ $\mathrm{NaOCl}$.

to the various disinfection methods could be detected. In combination with antibacterial irrigation using $1 \% \mathrm{NaOCl}$, no significant differences between the various disinfection methods could be observed.

The present ex vivo study employed a monospecies biofilm model inside the root canal of upper canines using E. faecalis. Upper canines exhibiting only one straight root canal with a standardized length of $19.5 \mathrm{~mm}$ were selected for the present study. After initial apical preparation up to ISO size 40, it can be assumed that uniform colonization of these root canals could be achieved. E. faecalis has been shown to be resistant against disinfecting agents and antibiotics [36] and can be effectively colonized; it forms a biofilm on root canal walls and invades dentinal tubules [37, 38]. Therefore, this monospecies biofilm model was used to reproduce the same biofilm-like structure in each of the investigated root canal samples with a species that is difficult to eliminate by chemomechanical debridement $[36,39]$. Successful biofilm formation could be validated by fluorescence microscopic imaging where colonization of the root canal walls as well as penetration into the dentinal tubules (Figure 2) could be clearly visualized.

Nevertheless, one requirement for laboratory studies that aim to investigate the antimicrobial effects of various disinfection methods is to use models that closely resemble in vivo conditions [40]. Consequently, multispecies biofilm models for root canal disinfection ex vivo have been developed [41]. However, for in vitro testing reproducible infection of the root canals is important. For that reason, a monospecies biofilm model using E. faecalis was applied; moreover, front teeth with straight root canals for achieving comparable bacterial loads and standardized sampling were used. Additionally,

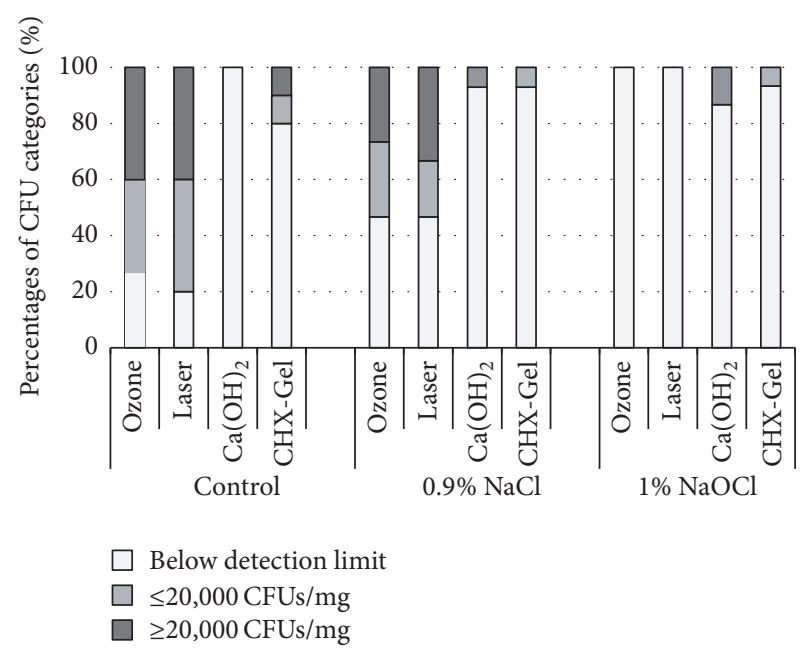

FIGURE 4: Percentile distribution of CFUs from adherent bacteria with respect to categories.

sampling of planktonic and adherent bacteria was conducted and further incubation of exemplary samples that demonstrated no bacterial growth immediately after treatment was performed with the aim of detecting remnant bacteria that could only be detected after further growing.

The present study design confirmed the effect of chemomechanical debridement using $1 \% \mathrm{NaOCl}$ compared to instrumentation of the root canal alone, as demonstrated previously [42]. $\mathrm{NaOCl}$ in concentrations of $1.0 \%$ and $5.0 \%$ has shown high antibacterial activity in a contact test [43], and residual $\mathrm{NaOCl}$ inside dentinal tubules has been regarded as crucial for effective disinfection [44]. In the present study, no blocking of $\mathrm{NaOCl}$ using sodium thiosulphate was performed, and consequently a continued effect of the applied disinfection protocol or a so-called carry-over effect inside the canal or the agar plate cannot be excluded [44]. Nevertheless, data on the carry-over effect of $\mathrm{NaOCl}$ are controversial and the effect seems to be negligible up to a $\mathrm{NaOCl}$ concentration of $3 \%[45,46]$.

The present study design allows conclusions about the antimicrobial effects of the various disinfection methods with respect to instrumentation and irrigation protocol. Without further instrumentation of the root canal, the antibacterial effects of the investigated medical dressings were significantly higher compared to laser or ozone treatment alone.

For ozone treatment alone, these results have been corroborated in a recent ex vivo study where gaseous ozone treatment for $120 \mathrm{~s}$ resulted in $100 \%$ of samples with $E$. faecalis regrowth [47]. Additionally, it has been demonstrated previously that ozone had little antibacterial effects on E. faecalis cells embedded in a biofilm structure [27]. Conversely, Huth et al. achieved complete elimination of $E$. faecalis biofilms after application of gaseous ozone in a high concentration of $53 \mathrm{~g} / \mathrm{m}^{3}$ for $1 \mathrm{~min}$ or lower concentrations with increased application time and concluded that the 
antibacterial effects of gaseous ozone were dose- and timedependent [31]. The optimum duration of application and concentration of gaseous ozone are still a matter of debate and may lead to inconsistent results of its antibacterial efficacy [26]. Application time of gaseous ozone was $60 \mathrm{~s}$ twice using the specific program of the device for root canal treatment. The applied ozone concentration was $2100 \mathrm{ppm}$ which resulted in $4.49 \mathrm{~g} / \mathrm{m}^{3}$. However, the device has been replaced on the market in the meantime by HealOzone X4 providing an ozone concentration of $32 \mathrm{~g} / \mathrm{m}^{3}$, which should be taken into consideration when interpreting the present results.

No significant differences in bacterial reduction could be demonstrated in the present study for the various investigated disinfection methods in combination of instrumentation and irrigation using $1 \% \mathrm{NaOCl}$ highlighting the fact that a one-visit root canal treatment including instrumentation and antibacterial irrigation in combination with adjunctive disinfection methods like ozone or diode laser application is equally effective compared to a simulated two-visit endodontic treatment with application of medical dressings.

The enhanced antimicrobial effect of gaseous ozone in combination with antibacterial irrigation using $\mathrm{NaOCl}$ has been also demonstrated in a recent in vitro study [25]. The cited authors speculated that disintegration of the bacterial biofilm using $\mathrm{NaOCl}$ might result in better penetration of ozone into the bacterial biofilm and the dentinal tubules. This supports the application of gaseous ozone as an adjunctive disinfection method in combination with an antibacterial irrigation protocol and instrumentation of the root canal. However, previous studies also demonstrated complete removal of $E$. faecalis after using solely $\mathrm{NaOCl}[25,48]$ questioning an additional antimicrobial effect of ozone. The present study also analyzed the long-term antimicrobial effect of the various disinfection methods with further incubation of exemplary samples of each group that demonstrated no bacterial growth immediately after treatment. Nearly $80 \%$ of ozone and laser treated samples revealed further bacterial growth whereas less than $50 \%$ of the samples with medical dressings showed further bacterial growth. These results also indicate little additional effects of the application of ozone of diode laser treatment in the present study. In this aspect, the abovementioned carry-over effect should be taken into consideration especially with the use of medical dressings. Parts of the active form of the medical dressings might have followed along with the sample into dilution series and possibly on the culture plate. A high enough concentration of the disinfectant might result in false negative results: the bacteria are not killed but might be hampered in growing because of the bacteriostatic effect. This might result in a too positive evaluation of the antibacterial methods tested [46]. In the present study, no blocking solutions for CHX like Tween 80 and alpha-lecithin or $\mathrm{Ca}(\mathrm{OH})_{2}$ like citric acid after the removal of the medical dressings have been applied and consequently the above described effects of overestimation of the antibacterial effects of the medical dressings cannot be excluded. Nevertheless, further effects of the mentioned blocking solutions can also not be excluded. Furthermore, the antibacterial effectiveness of calcium hydroxide is decreasing after application because of the reduced availability of hydroxyl ions in solution [9] and this also should minimize the carry-over effect. In addition, bacterial reduction was comparable between the application of medical dressings and irrigation using $\mathrm{NaOCl}$ and laser or ozone. Moreover, further bacterial growth in vivo might also be limited by complete three-dimensional root canal filling and further effects of medical dressings after incomplete removal might also occur.

In the present study, laser assisted disinfection revealed effective bacterial reduction in combination with antibacterial irrigation using $1 \% \mathrm{NaOCl}$ and was equally effective compared to the investigated medical dressings $\mathrm{Ca}(\mathrm{OH})_{2}$ and CHX-Gel or application of gaseous ozone for planktonic and adherent cells of $E$. faecalis.

These results were corroborated by a previous study that investigated the antibacterial effect of a $908 \mathrm{~nm}$ diode laser (2.5 W) on E. faecalis. E. faecalis was completely eliminated using antibacterial irrigation protocols with $\mathrm{NaOCl}$ [49]. Another study analyzed the antibacterial efficacy of diode laser irradiation $(940 \mathrm{~nm}, 3.5 \mathrm{~W})$ compared to three other root canal disinfection methods: conventional irrigation, EndoActivator, and PIPS (photon-initiated photoacoustic streaming). Samples that were treated with diode laser irradiation revealed the highest antibacterial efficacy against $E$. faecalis compared to all other methods [33]. Consequently, the combination of gaseous ozone or diode laser with chemomechanical canal enlargement and $\mathrm{NaOCl}$ irrigation may offer an approach to single-visit root canal treatments in endodontic therapy. Nevertheless, activation of antibacterial irrigation solutions, namely, $\mathrm{NaOCl}$, has not been analyzed in the present experimental approach and could also contribute to sufficient bacterial reduction in a single-visit endodontic treatment approach [10].

To date, a multiple-visit approach in endodontic therapy is still commonly performed. In a systematic review on nonsurgical single-visit versus multiple-visit endodontic treatment, Wong et al. described that up to $90 \%$ of clinical practitioners prefer a multiple-visit approach [23]. Hence, medical dressings still play an important role in endodontic therapy. $\mathrm{Ca}(\mathrm{OH})_{2}$ is the most frequently used intracanal medical dressing besides its questioned antimicrobial effectiveness [50]. The results of our investigation demonstrated significantly better antibacterial action of $\mathrm{Ca}(\mathrm{OH})_{2}$ and CHXGel (1\%) against planktonic and adherent cells of $E$. faecalis after using it for 7 days [42] compared to disinfection solely using diode laser or ozone without an antibacterial irrigation protocol. For planktonic bacteria, $\mathrm{Ca}(\mathrm{OH})_{2}$ demonstrated a significantly higher bacterial reduction compared to CHXGel. No significant differences were found comparing the antibacterial effectiveness of $\mathrm{Ca}(\mathrm{OH})_{2}$ and CHX-Gel (1\%) for adherent bacteria. These results were confirmed by a previous study where $\mathrm{Ca}(\mathrm{OH})_{2}$ was found to be as effective as $1 \% \mathrm{CHX}$ in reducing E. faecalis at 3 and 8 days [51]. Nevertheless, intracanal remnants of $\mathrm{Ca}(\mathrm{OH})_{2}$ hinder the sealing quality of root canal filling materials, putting a risk to reinfection of the root canal system after obturation. CHX-Gel is considered to be an alternative medical dressing to $\mathrm{Ca}(\mathrm{OH})_{2}$. This topic needs to be addressed in future studies. 


\section{Conclusion}

In summary, $\mathrm{Ca}(\mathrm{OH})_{2}$ was the most effective disinfection method against $E$. faecalis without any supportive irrigation protocols. Combining gaseous ozone and laser irradiation with $\mathrm{NaOCl}$ irrigation and instrumentation of the root canal resulted in comparable bacterial reductions of E. faecalis to application of medical dressings. Within the limitations of this in vitro study, it can be concluded that one-visit root canal treatment including antibacterial irrigation using $\mathrm{NaOCl}$ combined with instrumentation and adjunctive disinfection using ozone or laser achieved bacterial reductions of $E$. faecalis comparable to the application of medical dressings. This supports the option of sufficient bacterial reduction in a single-visit root canal treatment.

\section{Additional Points}

One-visit root canal treatment including antibacterial irrigation using $\mathrm{NaOCl}$ in combination with adjunctive disinfection like ozone or laser resulted in comparable bacterial reduction of $E$. faecalis to application of medical dressings simulating a multiple-visit endodontic treatment.

\section{Conflicts of Interest}

The authors declare that there are no conflicts of interest regarding the publication of this paper.

\section{Authors' Contributions}

Kerstin Bitter and Alexander Vlassakidis contributed equally to this paper.

\section{References}

[1] M. Haapasalo, Y. Shen, Z. Wang, and Y. Gao, "Irrigation in endodontics," British Dental Journal, vol. 216, no. 6, pp. 299-303, 2014.

[2] I. N. Rôças, J. F. Siqueira Jr., and K. R. Santos, "Association of Enterococcus faecalis with different forms of periradicular diseases," Journal of Endodontics, vol. 30, no. 5, pp. 315-320, 2004.

[3] J. F. Siqueira Jr. and I. N. Rôças, "Polymerase chain reactionbased analysis of microorganisms associated with failed endodontic treatment," Oral Surgery, Oral Medicine, Oral Pathology, Oral Radiology, and Endodontology, vol. 97, no. 1, pp. 85-94, 2004.

[4] J. F. Siqueira Jr., "Histological evaluation of the effectiveness of five instrumentation techniques for cleaning the apical third of root canals," Journal of Endodontics, vol. 23, no. 8, pp. 499-502, 1997.

[5] O. A. Peters, A. Laib, P. Rüegsegger, and F. Barbakow, “Threedimensional analysis of root canal geometry by high-resolution computed tomography," Journal of Dental Research, vol. 79, no. 6, pp. 1405-1409, 2000.

[6] J. F. Siqueira Jr. and I. N. Rôçac, "Diversity of endodontic microbiota revisited," Journal of Dental Research, vol. 88, no. 11, pp. 969-981, 2009.
[7] J. F. Siqueira Jr. and I. N. Rôças, "Clinical implications and microbiology of bacterial persistence after treatment procedures," Journal of Endodontics, vol. 34, no. 11, pp. 1291-1301.e3, 2008.

[8] G. Hasselgren, B. Olsson, and M. Cvek, "Effects of calcium hydroxide and sodium hypochlorite on the dissolution of necrotic porcine muscle tissue," Journal of Endodontics, vol. 14, no. 3, pp. 125-127, 1988.

[9] J. F. Siqueira Jr. and H. P. Lopes, "Mechanisms of antimicrobial activity of calcium hydroxide: a critical review," International Endodontic Journal, vol. 32, no. 5, pp. 361-369, 1999.

[10] M. Haapasalo and Y. Shen, "Current therapeutic options for endodontic biofilms," Endodontic Topics, vol. 22, pp. 79-98, 2012.

[11] I. Ethem Yaylali, A. D. Kececi, and B. Ureyen Kaya, "Ultrasonically activated irrigation to remove calcium hydroxide from apical third of human root canal system: a systematic review of in vitro studies," Journal of Endodontics, vol. 41, no. 10, pp. 1589-1599, 2015.

[12] J. Ma, Y. Shen, Y. Yang et al., "In vitro study of calcium hydroxide removal from mandibular molar root canals," Journal of Endodontics, vol. 41, no. 4, pp. 553-558, 2015.

[13] J. Z. Ma, Y. Shen, A. J. Al-Ashaw et al., "Micro-computed tomography evaluation of the removal of calcium hydroxide medicament from C-shaped root canals of mandibular second molars," International Endodontic Journal, vol. 48, no. 4, pp. 333-341, 2015.

[14] D. E. Böttcher, V. H. G. Hirai, U. X. Da Silva Neto, and F. S. Grecca, "Effect of calcium hydroxide dressing on the long-term sealing ability of two different endodontic sealers: an in vitro study," Oral Surgery, Oral Medicine, Oral Pathology, Oral Radiology, and Endodontology, vol. 110, no. 3, pp. 386-389, 2010.

[15] S. K. Kim and Y. O. Kim, "Influence of calcium hydroxide intracanal medication on apical seal," International Endodontic Journal, vol. 35, no. 7, pp. 623-628, 2002.

[16] B. Athanassiadis, P. V. Abbott, and L. J. Walsh, "The use of calcium hydroxide, antibiotics and biocides as antimicrobial medicaments in endodontics," Australian Dental Journal, vol. 52, no. 1, supplement, pp. S64-S82, 2007.

[17] A. Manzur, A. M. González, A. Pozos, D. Silva-Herzog, and S. Friedman, "Bacterial quantification in teeth with apical periodontitis related to instrumentation and different intracanal medications: a randomized clinical trial," Journal of Endodontics, vol. 33, no. 2, pp. 114-118, 2007.

[18] B. P. Figueiredo de Almeida Gomes, M. E. Vianna, N. T. Sena, A. A. Zaia, C. C. R. Ferraz, and F. J. de Souza Filho, "In vitro evaluation of the antimicrobial activity of calcium hydroxide combined with chlorhexidine gel used as intracanal medicament," Oral Surgery, Oral Medicine, Oral Pathology, Oral Radiology and Endodontology, vol. 102, no. 4, pp. 544-550, 2006.

[19] E. Schäfer and K. Bössmann, "Antimicrobial efficacy of chlorhexidine and two calcium hydroxide formulations against Enterococcus faecalis," Journal of Endodontics, vol. 31, no. 1, pp. 53-56, 2005.

[20] B. P. F. A. Gomes, S. F. C. Souza, C. C. R. Ferraz et al., "Effectiveness of $2 \%$ chlorhexidine gel and calcium hydroxide against Enterococcus faecalis in bovine root dentine in vitro," International Endodontic Journal, vol. 36, no. 4, pp. 267-275, 2003.

[21] L. Figini, G. Lodi, F. Gorni, and M. Gagliani, "Single versus multiple visits for endodontic treatment of permanent teeth," The Cochrane Database of Systematic Reviews, no. 4, Article ID CD005296, 2007. 
[22] A. W.-Y. Wong, C. S.-C. Tsang, S. Zhang, K.-Y. Li, C. Zhang, and C.-H. Chu, "Treatment outcomes of single-visit versus multiplevisit non-surgical endodontic therapy: a randomised clinical trial," BMC Oral Health, vol. 15, no. 1, article 162, 2015.

[23] A. W. Y. Wong, C. Zhang, and C.-H. Chu, "A systematic review of nonsurgical single-visit versus multiple-visit endodontic treatment," Clinical, Cosmetic and Investigational Dentistry, vol. 6, pp. 45-56, 2014.

[24] A. W.-Y. Wong, S. Zhang, S. K.-Y. Li, X. Zhu, C. Zhang, and C.-H. Chu, "Incidence of post-obturation pain after singlevisit versus multiple-visit non-surgical endodontic treatments," BMC Oral Health, vol. 15, no. 1, article 96, 2015.

[25] T. Boch, C. Tennert, K. Vach, A. Al-Ahmad, E. Hellwig, and O. Polydorou, "Effect of gaseous ozone on Enterococcus faecalis biofilm-an in vitro study," Clinical Oral Investigations, vol. 20, no. 7, pp. 1733-1739, 2016.

[26] A. Kishen, "Advanced therapeutic options for endodontic biofilms," Endodontic Topics, vol. 22, pp. 99-123, 2012.

[27] R. S. Hems, K. Gulabivala, Y.-L. Ng, D. Ready, and D. A. Spratt, "An in vitro evaluation of the ability of ozone to kill a strain of Enterococcus faecalis," International Endodontic Journal, vol. 38, no. 1, pp. 22-29, 2005.

[28] C. Estrela, D. A. Decurcio, A. C. B. Hollanda, and J. A. Silva, "Antimicrobial efficacy of ozonated water, gaseous ozone, sodium hypochlorite and chlorhexidine in infected human root canals," International Endodontic Journal, vol. 40, no. 2, pp. 8593, 2007.

[29] B. Üreyen Kaya, A. D. Kececi, H. E. Güldaş et al., "Efficacy of endodontic applications of ozone and low-temperature atmospheric pressure plasma on root canals infected with Enterococcus faecalis," Letters in Applied Microbiology, vol. 58, no. 1, pp. 8-15, 2014.

[30] R. Zan, I. Hubbezoglu, Z. Sümer, T. Tunç, and J. Tanalp, "Antibacterial effects of two different types of laser and aqueous ozone against Enterococcus faecalis in root canals," Photomedicine and Laser Surgery, vol. 31, no. 4, pp. 150-154, 2013.

[31] K. C. Huth, M. Quirling, S. Maier et al., "Effectiveness of ozone against endodontopathogenic microorganisms in a root canal biofilm model," International Endodontic Journal, vol. 42, no. 1, pp. 3-13, 2009.

[32] G. I. Jung, J. S. Kim, T. Lee et al., "Photomechanical effect on Type I collagen using pulsed diode laser," Technology and Health Care, vol. 23, supplement 2, pp. S535-S541, 2015.

[33] J. Mathew, J. Emil, B. Paulaian, B. John, J. Raja, and J. Mathew, "Viability and antibacterial efficacy of four root canal disinfection techniques evaluated using confocal laser scanning microscopy," Journal of Conservative Dentistry, vol. 17, no. 5, pp. 444-448, 2014.

[34] K. Anjaneyulu and M. S. Nivedhitha, "Influence of calcium hydroxide on the post-treatment pain in Endodontics: a systematic review," Journal of Conservative Dentistry, vol. 17, no. 3, pp. 200-207, 2014.

[35] N. Gutknecht, R. Franzen, M. Schippers, and F. Lampert, "Bactericidal effect of a 980-nm diode laser in the root canal wall dentin of bovine teeth," Journal of Clinical Laser Medicine and Surgery, vol. 22, no. 1, pp. 9-13, 2004.

[36] J. Sun, X. Song, B. E. Kristiansen et al., "Occurrence, population structure, and antimicrobial resistance of enterococci in marginal and apical periodontitis," Journal of Clinical Microbiology, vol. 47, no. 7, pp. 2218-2225, 2009.

[37] S. George, A. Kishen, and K. P. Song, "The role of environmental changes on monospecies biofilm formation on root canal wall by Enterococcus faecalis," Journal of Endodontics, vol. 31, no. 12, pp. 867-872, 2005.

[38] C. M. Sedgley, S. L. Lennan, and O. K. Appelbe, "Survival of Enterococcus faecalis in root canals ex vivo," International Endodontic Journal, vol. 38, no. 10, pp. 735-742, 2005.

[39] C. Tennert, K. Feldmann, E. Haamann et al., "Effect of photodynamic therapy (PDT) on Enterococcus faecalis biofilm in experimental primary and secondary endodontic infections," BMC Oral Health, vol. 14, article 132, 2014.

[40] Y. Shen, Y. Gao, J. Lin, J. Ma, Z. Wang, and M. Haapasalo, "Methods and models to study irrigation," Endodontic Topics, vol. 27, pp. 3-34, 2012.

[41] A. Kishen and M. Haapasalo, "Biofilm models and methods of biofilm assessment," Endodontic Topic, vol. 22, pp. 58-78, 2012.

[42] G. B. Shuping, D. Ørstavik, A. Sigurdsson, and M. Trope, "Reduction of intracanal bacteria using nickel-titanium rotary instrumentation and various medications," Journal of Endodontics, vol. 26, no. 12, pp. 751-755, 2000.

[43] L. M. Sassone, R. A. S. Fidel, S. R. Fidel, M. Dias, and R. J. Hirata, "Antimicrobial activity of different concentrations of $\mathrm{NaOCl}$ and chlorhexidine using a contact test," Brazilian Dental Journal, vol. 14, no. 2, pp. 99-102, 2003.

[44] S. Hecker, K.-A. Hiller, K. M. Galler, S. Erb, T. Mader, and G. Schmalz, "Establishment of an optimized ex vivo system for artificial root canal infection evaluated by use of sodium hypochlorite and the photodynamic therapy," International Endodontic Journal, vol. 46, no. 5, pp. 449-457, 2013.

[45] O. H. Muhammad, M. Chevalier, J.-P. Rocca, N. BrulatBouchard, and E. Medioni, "Photodynamic therapy versus ultrasonic irrigation: interaction with endodontic microbial biofilm, an ex vivo study," Photodiagnosis and Photodynamic Therapy, vol. 11, no. 2, pp. 171-181, 2014.

[46] G. Rossi-Fedele, J. A. P. de Figueiredo, L. Steier, L. Canullo, G. Steier, and A. P. Roberts, "Evaluation of the antimicrobial effect of super-oxidized water (Sterilox ${ }^{\circledR}$ ) and sodium hypochlorite against Enterococcus faecalis in a bovine root canal model," Journal of Applied Oral Science, vol. 18, no. 5, pp. 498-502, 2010.

[47] R. Noites, C. Pina-Vaz, R. Rocha, M. F. Carvalho, A. Gonçalves, and I. Pina-Vaz, "Synergistic antimicrobial action of chlorhexidine and ozone in endodontic treatment," BioMed Research International, vol. 2014, Article ID 592423, 6 pages, 2014.

[48] A. Kuştarci, Z. Sümer, D. Altunbaş, and S. Koşum, "Bactericidal effect of KTP laser irradiation against Enterococcus faecalis compared with gaseous ozone: an ex vivo study," Oral Surgery, Oral Medicine, Oral Pathology, Oral Radiology and Endodontology, vol. 107, no. 5, pp. e73-e79, 2009.

[49] T. Preethee, D. Kandaswamy, G. Arathi, and R. Hannah, "Bactericidal effect of the $908 \mathrm{~nm}$ diode laser on Enterococcus faecalis in infected root canals," Journal of Conservative Dentistry, vol. 15, no. 1, pp. 46-50, 2012.

[50] Z. Mohammadi and P. M. H. Dummer, "Properties and applications of calcium hydroxide in endodontics and dental traumatology," International Endodontic Journal, vol. 44, no. 8, pp. 697-730, 2011.

[51] A. Almyroudi, D. Mackenzie, S. McHugh, and W. P. Saunders, "The effectiveness of various disinfectants used as endodontic intracanal medications: an in vitro study," Journal of Endodontics, vol. 28, no. 3, pp. 163-167, 2002. 

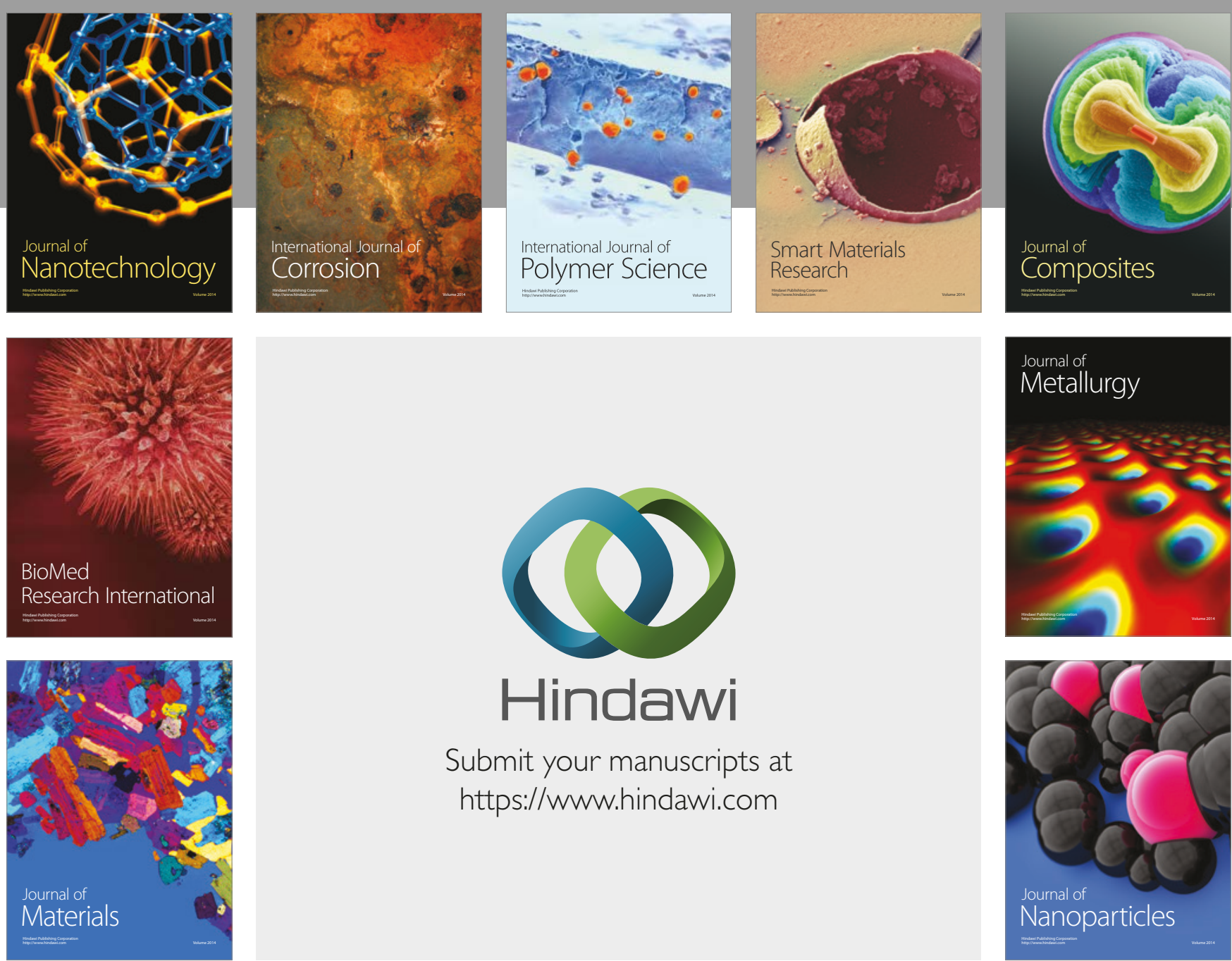

\section{Hindawi}

Submit your manuscripts at

https://www.hindawi.com
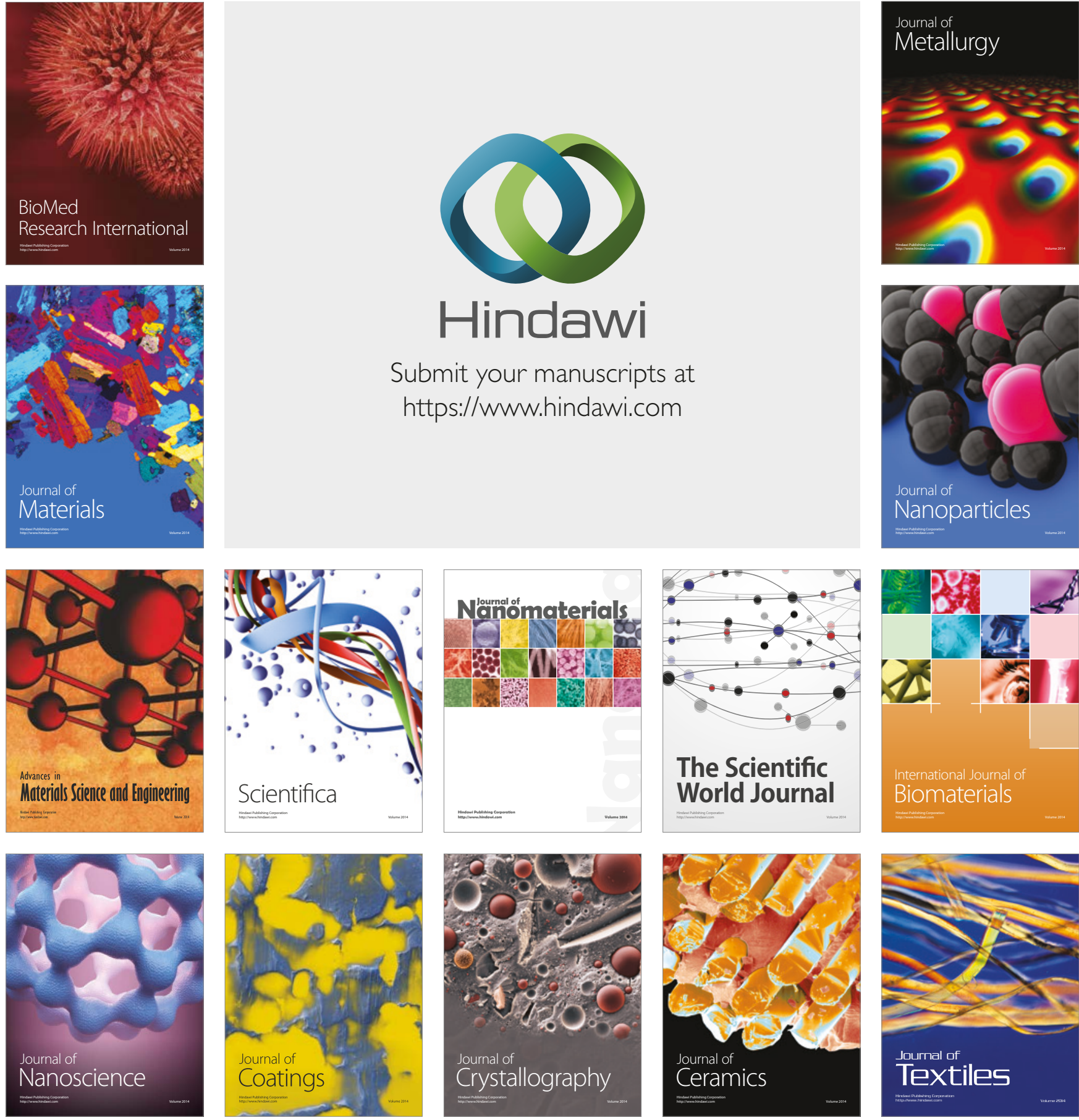

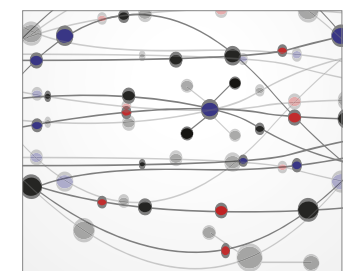

The Scientific World Journal
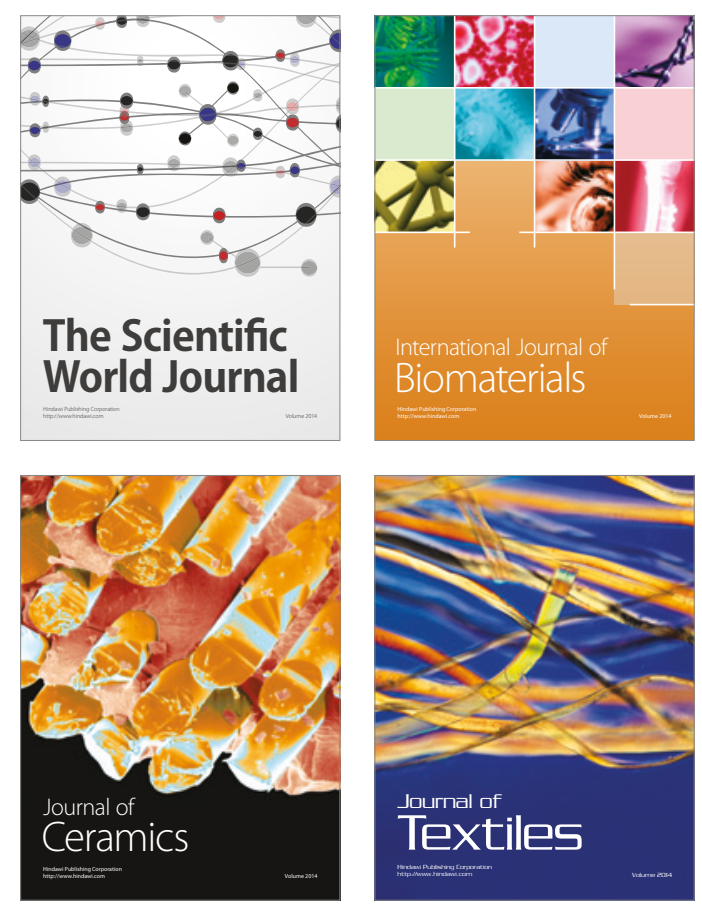